\title{
Adductor Pollicis Muscle Thickness and Obesity Are Associated with Poor Outcome after Stroke: A Cohort Study
}

\author{
Juli Thomaz de Souza, MSc, ${ }^{*}$ Marcos Ferreira Minicucci, PhD, \\ Leonardo Antônio Mamede Zornoff, PhD,* Bertha Furlan Polegato, PhD,* \\ Priscila Watson Ribeiro, PhD, + Silméia Garcia Zanati Bazan, PhD, ${ }^{*}$ \\ Gabriel Pereira Braga, PhD, † Gustavo José Luvizutto, PhD, $†$ \\ Sérgio Alberto Rupp de Paiva, $\mathrm{PhD},{ }^{*}$ Rodrigo Bazan, $\mathrm{PhD},+$ and \\ Paula Schmidt Azevedo, $\mathrm{PhD}^{*}$
}

\begin{abstract}
Background: Nutritional status may influence outcome after stroke. It is possible that some obese individuals present reduced fat-free mass. Aims: We aimed to determine if bedside evaluation of body composition by the body mass index (BMI), adductor pollicis muscle thickness (APMT) and arm muscle area (AMA), and the combination of low APMT or AMA with obesity are associated with disability 90 days after stroke. Methods: A cohort study evaluating 120 patients hospitalized at the Stroke Unit was carried out. Data were expressed as average \pm standard deviation or median and percentiles. Obesity was evaluated by BMI and fat-free mass by the APMT and AMA. Receiver operating characteristic (ROC) curves and multivariate logistic regression analysis were used to measure whether APMT and obesity were associated with modified Rankin Scale (mRS) $\geq 3$ (disability) within 90 days of stroke. The data were adjusted for National Institutes of Health Stroke Scale (NIHSS), sex, age, type of stroke, and thrombolysis. The significance level was 5\%. Results: Of 120 patients, we came up with the following demographics: men: $66(55.0 \%)$; mean age: $66.6 \pm 13.2$ years; ischemic stroke: 109 (90.8\%); mean NIHSS: 4 (2-10); thrombolysis: $18(16.5 \%)$. Considering $\mathrm{mRS} \geq 3$, ROC curve analysis showed that the value of the cutoff for APMT was $<12.5 \mathrm{~mm}$. In multivariate analysis adjusted for the above factors, each $1 \mathrm{~mm}$ of increase in APTM reduced the chance of disability by $31 \%$. The intersection of obesity with APMT $<12.5 \mathrm{~mm}$ increased by $37-$ fold the risk of disability. AMA was not associated with $\mathrm{mRS} \geq 3$. Conclusion: Lower APMT alone or in combination with obesity was associated with poor functional status. Key Words: Stroke-nutritional assessment-obesity-disability evaluation. (C) 2018 National Stroke Association. Published by Elsevier Inc. All rights reserved.
\end{abstract}

From the *Department of Internal Medicine, São Paulo State University (Unesp), Medical School, Botucatu, SP; and tDepartment of Neurology, Psychology and Psychiatry, São Paulo State University (Unesp), Medical School, Botucatu, SP, Brazil.

Received March 7, 2017; revision received December 18, 2017; accepted December 20, 2017.

Address correspondence to Juli Thomaz de Souza, MSc, São Paulo State University (Unesp), Medical School, Botucatu, District of Rubião Junior, Botucatu, SP 18618-970, Brazil.

Email: jtsouz@yahoo.com.br

1052-3057/\$ - see front matter

(C) 2018 National Stroke Association. Published by Elsevier Inc. All rights reserved.

https://doi.org/10.1016/j.jstrokecerebrovasdis.2017.12.028

\section{Introduction}

Stroke is a public health problem of the first order: it is the third leading cause of death in developed countries, behind cancer and heart diseases. ${ }^{1}$ Approximately $80 \%$ of all strokes are ischemic (due to occlusion of a vessel) and others are hemorrhagic. ${ }^{2}$ Stroke is considered the most disabling disease in adult life. ${ }^{3}$ Long-term disability is the most common complication after stroke. ${ }^{4}$

After the diagnosis of stroke, many scales are used, in clinical practice and trials, to objectively measure the deficits, severity, and prognosis after stroke. For instance, the 
National Institutes of Health Stroke Scale (NIHSS) is a quantitative scale of stroke-related neurological deficit that was developed for prospective clinical research ${ }^{5}$ and is useful to indicate disease severity and functional status. Another tool, the modified Rankin Scale (mRS) is used to assess functional outcome after stroke. The mRS score ranges from 0 to 6 , and the higher the value, the worse the prognosis. Scores from 0 to 2 imply none to low disability and no need for assistance to perform daily activities. Scores from 3 to 5 entail moderate to severe disabilities. Importantly, death is classified as a score of $6 .{ }^{6}$

Independently of the variables considered in severity and functional indexes, nutritional status has been investigated as an important factor with an impact on outcome after stroke. One example is obesity, which has reached epidemiological proportions in the last years and has been considered a risk factor for stroke. ${ }^{7}$ Nonetheless, some studies have shown that overweight and obese patients have a better functional status and lower mortality when compared with normal-weight or underweight people after stroke. The unexpected association between obesity and mortality has been described as the "obesity paradox." 8,9

On the other hand, undernourished patients have the worst prognosis after stroke when compared with normal, overweight, and obese patients. In fact, undernourished patients are more susceptible to infections, ulcers sores, muscle weakness, and mortality. ${ }^{10}$ Certainly, the problem of malnutrition is more evident and studied over the course of stroke. Stroke location, fatigue, motor impairment, visuospatial perceptual, depression, dysphagia, inflammation, anorexia, and cognitive deficits are all factors implicated in the development of malnutrition and disability after stroke. ${ }^{11}$ However, the prevalence of malnutrition at admission, which reflects nutritional status previously to stroke, varies between $8 \%$ and $40 \%$. Much of this variation may be attributed to different definitions of malnutrition and methods of assessment. ${ }^{10}$

In general, body composition and the diagnosis of obesity or underweight are evaluated by body mass index (BMI). However, this measure assesses only 1 body compartment. Thus, it is possible that patients with increased BMI may show a reduction in muscle mass. In fact, a recent study using dual-energy X-ray absorptiometry (DXA) showed that low muscle mass/low fat mass and low muscle mass/high fat mass had higher mortality than high muscle mass/low fat mass and high muscle mass / high fat mass. ${ }^{9}$

DXA is considered one of the gold standard methods for assessing muscle mass, bone mass, and fat mass. However, its cost is high, and it is not readily available in most services. Indeed, it is interesting to evaluate the role of simple anthropometric measurement methods to explain the functional capacity and death of patients after stroke. In this setting, adductor pollicis muscle thickness (APMT) and arm muscle area (AMA) are possible tools to estimate muscle mass. Moreover, the adductor pollicis is the only muscle that can be directly measured. ${ }^{12}$

Considering these risk factors for disability and death, the role of nutritional status at the admission of patients who have suffered stroke remains to be elucidated. The assessment of body composition in stroke patients is not easy. ${ }^{13}$ Thereby, the hypothesis of the present study is that abnormalities in anthropometric measures may be associated with disabilities 3 months after stroke. This study aims to evaluate if bedside muscle-mass assessment, measured by the APMT and AMA, obesity, and the association of low muscle mass with obesity, are related with poor functional status and mortality, 90 days after stroke, in patients admitted to a Stroke Unit.

\section{Methods}

\section{Setting, Participants, and Study Design}

This cohort study was approved by the Ethics Committee of the Botucatu Medical School. One hundred twenty consecutive patients over 18 years old admitted to the Stroke Unit with ischemic or hemorrhagic stroke were evaluated between April and December 2014. The exclusion criterion was the presence of neurological disease other than stroke. All patients were treated per specific protocols depending on the type of stroke.

Upon admission, demographic characteristics, stroke type and severity, and the percentage undergoing thrombolysis, were recorded. Stroke type (ischemic or hemorrhagic) was diagnosed according to magnetic resonance imaging or a computed tomography scan of the brain. Patients with ischemic stroke who met the required criteria were submitted to intravenous thrombolysis. Nutritional evaluation, including BMI, APMT, and AMA, were performed within the first 36 hours of admission, after clinical stabilization. All patients were followed for 90 days after hospital discharge. Functional outcome at 90 days was determined using the mRS.

\section{Measurement of Severity and Functional Indexes}

The NIHSS index was calculated as previously reported ${ }^{5}$ at admission, and this was the parameter used to define stroke severity. The mRS index was calculated as previously described, 690 days after stroke, and this was the parameter used to define disability, low functional capacity (mRS 3-5), and mortality (mRS 6).

\section{Anthropometric Measurements}

\section{Body Mass Index}

Body weight was measured with a Filizola balance. Patients who were bed-restricted had their weight and height estimated by using the measurement of mid-arm circumference (MAC) and knee height, as described in References 14,15 to compose the Chumlea (1988) and Blackburn (1979) 
Table 1. Characteristics of patients during hospitalization for stroke separated by mRS evaluated 90 days after hospital discharge

\begin{tabular}{lccc}
\hline & $\operatorname{mRS}<3(83)$ & $\operatorname{mRS} \geq 3(37)$ & $P$ \\
\hline Male gender $(\% \mathrm{n})$ & $56.6(47.0)$ & $51.4(19.0)$ & .736 \\
Age $(\mathrm{y})$ & $68.0(57.0-72.0)$ & $75.0(66.0-80.0)$ & .002 \\
NIHSS & $3(2.0-5.0)$ & $11.5(7.2-17.5)$ & $<.001$ \\
Ischemic stroke $(\% \mathrm{n})$ & $92.8(77.0)$ & $86.5(32.0)$ & .44 \\
Hemorrhagic stroke $(\% \mathrm{n})$ & $7.2(6.0)$ & $13.5(5.0)$ & .44 \\
Thrombolysis $(\% \mathrm{n})$ & $13.3(11.0)$ & $18.9(7.0)$ & .55 \\
\hline
\end{tabular}

Abbreviations: mRS, modified Rankin Scale; NIHSS, National Institutes of Health Stroke Scale.

Performed $t$ test for age and NIHSS. Performed chi-square for type of stroke, sex, and thrombolysis. The results were expressed as mean \pm standard deviation and median and percentiles.

formula, as previously described. ${ }^{13,16}$ BMI was calculated according to the Quetelet equation $\left(\mathrm{BMI}=\right.$ weight $/$ height $\left.^{2}\right) \cdot{ }^{17}$ Obesity was considered a BMI $\geq 30 \mathrm{~kg} / \mathrm{m}^{2}$ and underweight was considered a BMI $<18.4 \mathrm{~kg} / \mathrm{m}^{2}$ for adults and $<23 \mathrm{~kg} / \mathrm{m}^{2}$ for the elderly. ${ }^{18,19}$

\section{Circumferences and Skinfold}

MAC was obtained using a measuring tape, as previously described. Triceps skinfold (TSF) was measured by using a Lange skinfold caliper (Beta Technology, Santa Cruz, CA), as previously described. ${ }^{20}$ AMA were evaluated using the respective formula: AMA $\left(\mathrm{cm}^{2}\right)=\left[\mathrm{MAC}-(\pi \times \mathrm{TSF})^{2} / 4 \pi\right]$ and to adjust for the area of the bone and obtain the bone-free AMA, for men was subtracted $10 \mathrm{~cm}^{2}$ for women was subtracted $6.5 \mathrm{~cm}^{2} .^{21}$ The same researcher performed all measurements.

\section{Adductor Pollicis Muscle Thickness}

APMT measurement ( $\mathrm{mm}$ ) was carried out using a Lange skinfold caliper (Beta Technology). The measurements were obtained from the unaffected arm flexed on the abdomen, with patients lying in bed. APMT was measured with the skinfold caliper in the vertex of an imaginary triangle formed by the extension of the thumb and index finger, under a continuous pressure of $10 \mathrm{~g} /$ $\mathrm{mm}$. The mean of 3 measurements was used.

\section{Statistical Analysis}

Variables were expressed as mean \pm standard deviation or median and percentiles. An ROC curve was drawn to determine the cutoff value of APMT that indicates mRS $\geq 3$. Multivariate logistic regression analysis was used to assess whether obesity, APMT, AMA, and the concurrence of obesity and low APMT were associated with $\mathrm{mRS}$ $\geq 3$ ninety days after the event. Logistic regressions were adjusted by NIHSS, sex, age, type of stroke, and thrombolysis. These are considered known factors that influence outcomes after stroke. The significance level accepted was 5\%. Sigma Plot 12.0 (Dundas Software LLC, Germany) was used to perform the analysis.

\section{Results}

One hundred fifty patients were assessed from April to December 2014. Twenty-eight patients were not included because stroke diagnosis was not confirmed by computed tomography. Two patients did not return for clinical evaluation. One hundred twenty subjects were included.

The baseline demographic data showed that the mean age was $66.6 \pm 13.2$ years, 66 (55\%) were male, 109 (90.8\%) presented with ischemic stroke, $11(9.2 \%)$ presented with hemorrhagic stroke, the hospital stay was $7 \pm 4$ days, and the mean NIHSS was $4 .{ }^{2-10}$ Among these patients, 18 (16\%) were subjected to thrombolysis, $37(30.8 \%)$ presented mRS 3-5 after 90 days, and 12 patients died (10\%). The baseline anthropometric measurements showed BMI: $26.9 \pm 5.1 \mathrm{~kg} / \mathrm{m}^{2}, \quad$ APMT: $12.6 \pm 4.4 \mathrm{~mm}$, AMA: $38.7 \pm 12.6 \mathrm{~cm}^{2}, 32(26.6 \%)$ patients were obese, and 17 $(14.2 \%)$ patients were underweight.

In patients with $m R S \geq 3$ after 90 days, higher NIHSS $(P<.001)$ and lower APMT were observed $(P<.001)$ (Tables 1 and 2). The ROC curve evidenced that the cutoff point of APMT was <12.5 mm (Fig 1).

In logistic regression analysis, the lowest thickness of $\mathrm{APM}$ was associated with $\mathrm{mRS} \geq 3$. Isolated obesity did

Table 2. Association between nutritional assessment results evaluated during hospitalization and mRS evaluated 90 days after hospital discharge

\begin{tabular}{lllc}
\hline & & & \\
& $\mathrm{mRS}<3(83)$ & $\mathrm{mRS} \geq 3(37)$ & $\mathrm{P}$ \\
\hline BMI $\left(\mathrm{kg} / \mathrm{m}^{2}\right)$ & $26.7 \pm 4.6$ & $27.5 \pm 6.0$ & .21 \\
Underweight $(\% \mathrm{n})$ & $13.3(11.0)$ & $16.2(6.0)$ & .88 \\
Obesity $(\% \mathrm{n})$ & $25.3(21.0)$ & $29.7(11.0)$ & .77 \\
APMT $(\mathrm{mm})$ & $13.7 \pm 4.2$ & $9.8 \pm 3.6$ & $<.001$ \\
AMA $\left(\mathrm{cm}^{2}\right)$ & $37.2 \pm 11.9$ & $41.0 \pm 13.7$ & .14 \\
\hline
\end{tabular}

Abbreviations: AMA, arm muscle area; APMT, adductor pollicis muscle thickness; BMI, body mass index.

Performed $t$ test for BMI, APMT, and AMA. Performed chisquare for underweight and obesity. The results were expressed as mean \pm standard deviation and median and percentiles. 


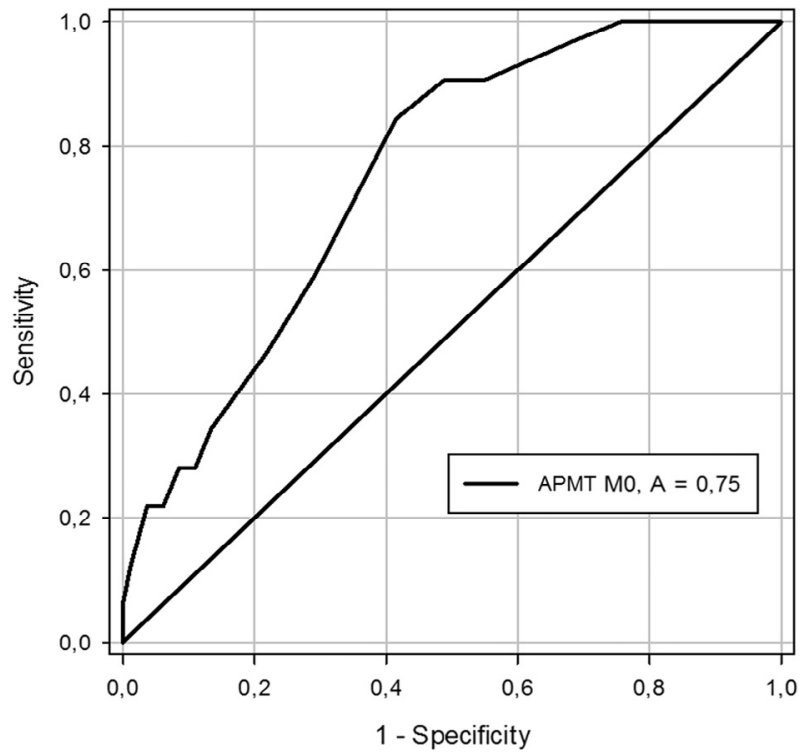

Figure 1. Areas under the receiver operating characteristic (AUROC) curve for adductor pollicis muscle thickness values.

not increase the risk of poor outcome, but the combination of obesity and APMT less than $12.5 \mathrm{~mm}$ was associated with a 37-fold increase in the probability of a poor outcome. The AMA was not associated with poor outcome after stroke (Table 3).

\section{Discussion}

This study evaluated patients with ischemic and hemorrhagic stroke at hospital admission in the Stroke Unit and 90 days later. In the hospital, demographic setting and severity index were recorded. Most diagnoses were ischemic stroke and $16.5 \%$ of them were eligible for thrombolysis. Nutritional evaluation was performed and showed that the mean BMI of the subjects placed them in the overweight category. After 90 days, the mRS index was

Table 3. Variables evaluated during hospitalization associated with the $m R S \geq 3$ evaluated 90 days after hospital discharge

\begin{tabular}{lrcc}
\hline \multicolumn{1}{c}{ Variables } & OR & CI 95\% & $P$ \\
\hline Obesity* & 2.16 & $.405-11.606$ & .36 \\
APMT $(\mathrm{mm})^{*}$ & .76 & $.613-0.951$ & .016 \\
AMA $\left(\mathrm{cm}^{2}\right)^{*}$ & 1.00 & $.95-1.06$ & .823 \\
Obesity and APMT & 37.05 & $2.30-595.04$ & .011 \\
$\quad<12.5 \mathrm{~mm}^{*}$ & & & \\
\hline
\end{tabular}

Abbreviations: AMA, arm muscle area; APMT, adductor pollicis muscle thickness; CI, confidence interval; NIHSS, National Institutes of Health Stroke Scale; OR, odds ratio.

*Variables evaluated separately by multivariate logistic regression and adjusted according to confounders (age, sex, NIHSS, thrombolysis, and type of stroke). calculated to evaluate functional capacity and death. The present work showed that low APMT and the concomitant presence of obesity and APMT less than $12.5 \mathrm{~mm}$ were associated with poor outcome 90 days after stroke. We highlight that methods used to assess body composition are simple and feasible in the Stroke Unit setting.

The assessment of functional status after stroke remains a challenge. In our study, $30.8 \%$ of patients had some degree of disability 90 days after stroke with $\mathrm{mRS} \geq 3$. This finding is similar to those of Oliveira, who observed that $30 \%$ of stoke patients become unable to walk without assistance. ${ }^{4}$ In the present study, we observed a $10 \%$ mortality rate. This value was consistent with other studies in stroke units, which indicated mortality from $8 \%$ to $19 \%$ in different countries. ${ }^{22-25}$

Nutritional status may influence the functional capacity of patients who suffered from stroke. In our study, we used bedside evaluation, such as APMT and AMA, to estimate muscle mass. These anthropometric measurements can be of great value to predict a possible reduction in muscle mass. Anthropometric measurements were compared with body composition measurements obtained by bioelectrical impedance in patients with stroke, and the authors found that anthropometric measurements, including the APMT and arm muscle circumference, may predict lean body mass reduction in these patients. ${ }^{4}$

Recently, it was observed that APTM has a moderate correlation with lean body mass in healthy people, suggesting that APMT may be useful and can be used in combination with other methods. ${ }^{26}$ In surgical patients, the measurement of APMT was significantly associated with nutritional status. ${ }^{27}$ Regarding the possibility of using APMT to measure muscle mass, this purpose has been considered important to estimate prognosis. In critically ill patients, the APMT values were associated with mortality. ${ }^{28,29}$ In cirrhotic patients, lower amounts of APMT were associated with higher degrees of hepatic encephalopathy. ${ }^{30}$

In our study, we found a mean APMT value of $13.7 \pm 4.2 \mathrm{~mm}$ in patients with $\mathrm{mRS}<3$. The value we found was similar to a study of 421 healthy individuals conducted to standardize the measurement of APMT in healthy adults, with values of $12.5 \pm 2.8 \mathrm{~mm}$ for men and $10.5 \pm 2.3 \mathrm{~mm}$ for women. ${ }^{31,32}$

The value of APMT was higher in the group with mRS $<3$ than in the $\mathrm{mRS} \geq 3$ group, showing the importance of this parameter. Another way to analyze the APMT is to show the association with functional capacity by applying the ROC curve. The AUC was .75 and defined $12.5 \mathrm{~mm}$ as the cutoff point. When evaluating the association between APMT and functional capacity using logistic regression, we found that each increase of 1 unit of APMT implies a 30\% decrease in the likelihood of functional disability, even when adjusted by factors known to influence the prognosis after stroke. Thus, the measurement of APMT is associated with significant clinical 
outcomes such as functional capacity. Furthermore, in our study, patients were evaluated in the first 36 hours after stroke; thus, the measure of APMT reflects the nutritional status prior to the stroke. Considering the hypothesis that higher muscle mass protects against poor outcomes, preserved muscle mass reflects better glucose metabolism, better fitness, and genetic predisposition, and lowers systemic inflammation. ${ }^{9}$

Regarding the AMA values, ours are below the 10th percentile compared with the American population data. ${ }^{21}$ In seeking Brazilian data, we found 3 studies with AMA data: (1) In 429 elderly people living in an urban area in southern Brazil, the average values of AMA were $49.0 \pm 15.7 \mathrm{~cm}^{2}$ for men and $45.8 \pm 16.3 \mathrm{~cm}^{2}$ for women. ${ }^{33}$ (2) In 483 ambulatory elderly residents in northeast of Brazil, the AMA mean values were $40.9 \pm 10.4 \mathrm{~cm}^{2}$ for men and $34.9 \pm 12.6 \mathrm{~cm}^{2}$ for women, ${ }^{34}$ and, finally, (3) in 26 hospitalized patients (62\% women), the average AMA value was $33.7 \pm 11.0 \mathrm{~cm}^{2} .{ }^{35}$ Hence, our AMA values are consistent with the findings in Brazilian literature. The use of international standards to interpret the data on Brazilian populations should be avoided, because this type of procedure can lead to the tendency to underestimate the muscle mass of patients. Also, we did not find any association between the AMA values and functional capacity in patients with stroke.

Recently, some important studies have shown a possible protective role of overweight and obesity after stroke. ${ }^{8,10,36}$ However, the reasons why obesity protects against poor outcomes are not known. In our study, we found an obesity rate from $25 \%$ to $29 \%$ of patients. This frequency is greater than the percentage of obese adults found in the Brazilian population; for example, a population-based study showed that in all 27 cities in Brazil, the frequency of obese adults was $16.8 \%{ }^{37}$ It is important to note that the presence of obesity is a risk factor for stroke. ${ }^{38,39}$ However, obesity was not associated with functional capacity.

Finally, patients may be obese and have low values of APMT. This group of patients is 37 times more likely to have a disability. These results suggest a worse prognosis when obesity is associated with reduced APMT. In fact, our study used bedside anthropometric methods to estimate muscle mass and BMI, and the results should be confirmed using more complex methods. However, these data suggest that concomitant low muscle mass and high fat mass leads to poor outcomes. In the same way, a previous study using DXA showed that low muscle associated with high or low fat increased mortality. The reasons why obesity associated with low muscle exerts additional adverse effects on general outcomes remains to be elucidated but includes higher inflammation and insulin resistance. ${ }^{7,9}$

Few published data have assessed body composition in more than 1 compartment, involving lean and fat mass. APMT, weight, and stature are simple, inexpensive, and feasible at the bedside. Low APMT was previously evaluated in healthy people and in patients with stroke. ${ }^{4,26}$ In addition, in diseases such as surgical, critical, and cirrhotic patients, the APMT was associated to poor prognosis. ${ }^{27-30}$ The present study hypothesized that APM is a potential tool to predict prognosis after stroke. From now on, it will be necessary to carry out new studies on a larger scale to prove this applicability. Therefore, APMT and BMI are potential tools to be used as markers of poor outcome after stroke, and may lead to more intensive nutritional interventions.

\section{Conclusion}

Low APMT was associated with poor functional outcome, independently of age, gender, type of stroke, thrombolysis, and NIHSS. Low APMT and concomitant obesity increase the risk of disabilities.

\section{References}

1. Lausada N, Arnal N, Astiz M, et al. Dietary fats significantly influence the survival of penumbral neurons in a rat model of chronic ischemic by modifying lipid mediators, inflammatory biomarkers, NOS production and redox-dependent apoptotic signals. Nutrition 2015;31:1430-1442.

2. Burgos PR, Segurola GH, Breton LI. Nutritional support in stroke patients. Nutr Hosp 2014;24(2 Suppl):57-66.

3. Scherbakov N, Sandek A, Doehner W. Stroke-related sarcopenia: specific characteristics. J Am Med Dir Assoc 2015;16:272-276. doi:10.1016/j.jamda.2014.12.007. Published online Feb 10.

4. Oliveira DS. Análise do perfil epidemiológico de pacientes com acidente vascular encefálico atendidos na clínica escola de saúde do UNIFOR MG. Minas Gerais. Monografia [Bacharelado em fisioterapia] - Centro Universitário de Formiga; 2013.

5. Kameshwar P, Deepa D, Amit K. Validation of the Hindi version of National Institute of Health Stroke Scale. Neurol India 2012;60:40-44. doi:10.4103/0028-3886.93587.

6. Caneda MAG, Fernandes JG, Almeida AG, et al. Confiabilidade de escalas de comprometimento neurológico em pacientes com acidente vascular cerebral. Arq Neuropsiquiatr 2006;64(3-A):690-697.

7. Bhupathiraju SN, Hu FB. Epidemiology of obesity and diabetes and their cardiovascular complications. Circ Res 2016;118:1723-1735. doi:10.1161/CIRCRESAHA.115.306825.

8. Doehner W, Schenkel J, Anker SD, et al. Overweight and obesity are associated with improved survival, functional outcome and stroke recurrence after acute stroke or transient ischaemic attack: observations from the TEMPiS trial. Eur Heart J 2013;34:268-277. doi:10.1093/eurheartj/ ehs340. Published online Oct 16.

9. Srikanthan $\mathrm{P}$, Horwich $\mathrm{TB}$, Tseng $\mathrm{CH}$. Relation of muscle mass and fat mass to cardiovascular disease mortality. Am J Cardiol 2016;117:1355-1360. doi:10.1016/ j.amjcard.2016.01.033. Published online Feb 2.

10. FOOD Trial Collaboration. Poor nutritional status on admission predicts poor outcomes after stroke: observational data from the FOOD trial. Stroke 2003;34:1450-1456. doi:10.1161/01.STR.0000074037.49197.8C. Published online May 15. 
11. Foley NC, Martin RE, Salter KL, et al. A review of the relationship between dysphagia and malnutrition following stroke. J Rehabil Med 2009;41:707-713. doi:10.2340/16501977-0415.

12. Lameu EB, Gerude MF, Corrêa RC, et al. Adductor pollicis muscle: a new anthropometric parameter. Rev Hosp Clin Fac Med Sao Paulo 2004;59:57-62. Published online Apr 26.

13. Chumlea WC, Guo S, Roche AF, et al. Prediction of body weight for the non-ambulatory elderly from anthropometry. J Am Diet Assoc 1988;88:564-568.

14. Callaway CW, Chumlea WC, Bouchard C, et al. Circumferences. In: Lohman TG, Roche AF, Martorell R, eds. Anthropometric standardizing reference manual. Champaign, IL: Human Kinetics Books, 1991:39-54.

15. Chumlea WC, Roche AF, Steinbaugh ML. Estimating stature from knee height for persons 60 to 90 years of age. J Am Geriatr Soc 1985;33:116-120.

16. Blackburn GL, Thornton BR. Nutritional assessment of the hospitalized patient. Med Clin North Am 1979;63:1103-1115.

17. Garrow JS, Webster J. Quetelet's index (W/H2) as a measure of fatness. Int J Obes 1985;9:147-153.

18. WHO. Obesity: preventing and managing the global epidemic. Report of a WHO Consultation. WHO Technical Report Series 894. Geneva: World Health Organization; 2000.

19. OPAS. Organización Panamericana de la Salud. Reunión del Comitê Asesor de Investigaciones en Salud. Encuestra Multicêntrica. Salud Beinestary Envejecimeiento (SABE) en América Latina e el Caribe. 2001. Available at: http://www1.paho.org/Spanish/HDP/HDR/CAIS-0105.PDF. Accessed May 6, 2016.

20. Harrison GG, Buskirk EK, Carter JEL, et al. Skinfold thicknesses and measurements technique. In: Lohman TG, Roche AF, Martorell R, eds. Anthropometric standardizing reference manual. Champaign, IL: Human Kinetics Books, 1991:55-80.

21. Frisancho AR. Anthropometric standards for the assessment of growth and nutritional status. Michigan: The University of Michigan Press, 1990:48-53.

22. Myint PK, Kidd AC, Kwok CS, et al. Time to computerized tomography scan, age, and mortality in acute stroke. J Stroke Cerebrovasc Dis 2016;doi:10.1016/ j.jstrokecerebrovasdis.2016.08.020. Published online Aug 20.

23. Kalèdienè R, Rastenytė D. Trends and regional inequalities in mortality from stroke in the context of health care reform in Lithuania. Medicina (Kaunas) 2016;52:244249. doi:10.1016/j.medici.2016.06.003. Published online Jul 29.

24. Rocha MS, Almeida AC, Abath Neto O, et al. Impact of stroke unit in a public hospital on length of hospitalization and rate of early mortality of ischemic stroke patients. Arq Neuropsiquiatr 2013;71:774-779. doi:10.1590/0004-282X20130120.

25. Zhu HF, Newcommon NN, Cooper ME, et al. Impact of a stroke unit on length of hospital stay and in-hospital case fatality. Stroke 2009;40:18-23. doi:10.1161/ STROKEAHA.108.527606. Published online 2008 Nov 13.
26. Bielemann RM, Horta BL, Orlandi SP, et al. Is adductor pollicis muscle thickness a good predictor of lean mass in adults? Clin Nutr 2015;7:doi:10.1016/j.clnu.2015.07.022.

27. Gonzalez MC, Pureza Duarte RR, Orlandi SP, et al. Adductor pollicis muscle: a study about its use as a nutritional parameter in surgical patients. Clin Nutr 2015;34:1025-1029. doi:10.1016/j.clnu.2014.11.006.

28. Ghorabi S, Ardehali H, Amiri Z, et al. Association of the adductor pollicis muscle thickness with clinical outcomes in intensive care unit patients. Nutr Clin Pract 2016;31:523-526. doi:10.1177/0884533615621547. Published online Feb 11.

29. Caporossi FS, Caporossi C, Borges Dock-Nascimento D, et al. Measurement of the thickness of the adductor pollicis muscle as a predictor of outcome in critically ill patients. Nutr Hosp 2012;27:490-495. doi:10.1590/S021216112012000200021

30. Augusti L, Franzoni LC, Santos LA, et al. Lower values of handgrip strength hand adductor pollicis muscle thickness are associated with hepatic encephalopathy manifestations in cirrhotic patients. Metab Brain Dis 2016;31:909-915. doi:10.1007/s11011-016-9828-8. Published online Apr 30.

31. Lavie CJ, De Schutter A, Parto P, et al. Obesity and prevalence of cardiovascular diseases and prognosis-the obesity paradox updated. Prog Cardiovasc Dis 2016;58:537-547. doi:10.1016/j.pcad.2016.01.008. Published online Jan 28.

32. Lameu EB, Gerude MF, Campos AC, et al. The thickness of the adductor pollicis muscle reflects the muscle compartment and may be used as a new anthropometric parameter for nutritional assessment. Curr Opin Clin Nutr Metab Care 2004;7:293-301.

33. Sass A, Marcon SS. Anthropometric measures comparison of elderly residents in urban area in southern Brazil by sex and age group. Rev Bras Geriatr Gerontol 2015;18:361-372. doi:10.1590/1809-9823.2015.13048.

34. Menezes TN, Marucci MFN. Trends in body fat and muscle mass among elderly individuals in Fortaleza, Ceará State, Brazil. Cad Saúde Pública 2007;23:2887-2895. doi:10.1590/S0102-311X2007001200010.

35. Maia JB, Santos MB, Simões TMR, et al. Espessura do músculo adutor do polegar como preditor do estado nutricional. Rev ENAF Sci 2016;11:38-43.

36. Olsen TS, Dehlendorff C, Petersen HG, et al. Body mass index and post stroke mortality. Neuroepidemiology 2008;30:93-100. doi:10.1159/000118945. Published online Feb 29.

37. Ministério da Saúde. Agência nacional de saúde suplementar. Vigitel Brasil 2014: vigilância de fatores de risco e proteção para doenças crônicas por inquérito telefônico. Brasília, DF, 2015.

38. Sabóia RS, Araújo AP, Barbosa MA, et al. Abdominal obesity and associated factors among adults attending a university health center. Rev Bras Prom Saúde 2016;29:259-267.

39. Grochovski CS, Campos R, Lima MCAM. Actions to control of damage to health in individuals with stroke. R Brasci Saúde 2015;19:269-276. doi:10.4034/ RBCS.2015.19.04.03. 